\title{
10 health stories that mattered: July 21-25
}

- Some medical marijuana companies are sending representatives to doctors' offices in an attempt to persuade hesitant physicians to recommend the drug to their patients. This is a frightening development, according to CMA President Dr. Louis Hugo Francescutti, given the insufficient evidence showing that cannabis is an effective medical product.

- Ontario will ask the federal government to pay its \$2-million bill for providing basic medical services to refugees. A recent Federal Court ruling deemed the federal government's funding cuts for refugee health care to be unconstitutional and "cruel and unusual treatment."

- E-cigarettes should be regulated the same as tobacco products, advertising should have limits, and the amount of allowable nicotine should be set by Health Canada, recommends the public health department of Montréal. Claims of efficacy should also be disallowed until there is more clinical evidence, recommends the department.
- Labels on packaged beef will soon have to indicate if the meat has been mechanically tenderized. The tenderizing process may move $E$. coli on the surface of beef into its centre, making it more difficult to kill during cooking.

- Ontario is moving forward in its attempt to ban payments for blood and blood plasma to ensure the poor aren't exploited or coerced into making donations. Exceptions will be made for research and emergency collection following catastrophic events.

- A Health Canada inspection of GlaxoSmithKline's influenza vaccine-producing facility in Ste. Foy, Quebec, found 10 issues that need to be addressed. The problems pose no risk to public health, though seven of them pertain to substandard production practices.

- The federal government has pledged \$5 million to UNICEF for improving the health of children and mothers in Somalia. The money will be used to target several areas of concern, including maternal and child deaths and nutrition.
- Raw milk can contain harmful bacteria such as Salmonella, E. coli and Listeria, and drinking it is not worth the risk, warns Health Canada. The pasteurization process does not affect the nutritional properties of milk, states Health Canada, though some Canadians believe it does and think raw milk is safer and healthier.

- Quebec police officers need better training to identify and handle mental health crises, according to a coroner's report on the death of Farshad Mohammadi, a homeless man shot and killed by Montréal police officers in 2012. Proper training can help officers differentiate between willful disobedience and mental confusion or distress.

- The mayor of La Prairie, Quebec, died after being stung multiple times by wasps. It is not known if Lucie Roussel, 51, had an allergic reaction, but experts note that dying from the direct effects of insect venom is rare. — Roger Collier, CMAJ

CMAJ 2014. DOI:10.1503/cmaj.109-4865 